\title{
ENTRE AS RIMAS DO CORDEL
}

\section{ARTIGO ORIGINAL}

SILVEIRA, Karla De Lourdes ${ }^{1}$

SILVEIRA, Karla De Lourdes. Entre as rimas do cordel. Revista Científica Multidisciplinar Núcleo do Conhecimento. Ano 05, Ed. 07, Vol. 01, pp. 71-86. Julho de 2020. ISSN: 2448-0959,

Link de acesso: https://www.nucleodoconhecimento.com.br/letras/rimas-do-cordel

\section{RESUMO}

Os Parâmetros Curriculares Nacionais, (PCN's-1998), sugerem um ensino contextualizado, que potencialize o diálogo que percorre a cultura popular e a erudita, aprimorando os educandos, em uma sociedade multicultural. Muitas são as formas de cultura popular que são mantidas ao longo do tempo, como é o caso da Literatura de Cordel, um gênero que sustenta forte acervo de aspectos e visões de mundo que merece ser observado e aprofundado de maneira crítica em sala de aula. Nessa perspectiva esse artigo tem como objetivo analisar a importância da inclusão do Cordel como uma ferramenta em sala de aula no processo de ensino-aprendizagem e como este gênero pode auxiliar o professor a trabalhar novas habilidades e novos saberes junto aos alunos, de forma criativa e conexa. A metodologia aplicada foi através de uma pesquisa básica, bibliográfica de natureza qualitativa, trazendo os elementos mais significativos deste gênero e traduzindo para o ensino os aspectos mais relevantes, com base teórica nos estudos de Bakhtin e Marchushi. Considerando a abordagem realizada, o Cordel é um gênero tipicamente multicultural em sua formação, ele percorre várias áreas dentro do ensino da Língua Portuguesa, promovendo aos alunos uma reflexão crítica, que pode ser alçada com a leitura dos folhetos, ampliando o conhecimento de mundo, gerando conscientização sobre as contradições que existem na sociedade e as possíveis relações entre o popular e o

\footnotetext{
${ }^{1}$ Graduada em Letras Língua Portuguesa (Licenciatura Plena).
} 
erudito, além de desenvolver a capacidade linguística do aluno, tornando-o cidadão pleno em uma sociedade letrada.

Palavras-Chave: Ensino, gênero, literatura de Cordel.

\section{INTRODUÇÃO}

A cultura popular surge de costumes e tradições transmitidos de geração para geração, ela passou por diversas fases de incompreensão no passado e continua ainda em boa parte desconhecida e muitas vezes negada implícita ou explicitamente, por conta da origem humilde que gerou concepções e pontos de vista divergentes entre pesquisadores e estudiosos. Ao longo do tempo houve grandes transformações sociais para que se iniciasse um processo de valorização da arte sem diploma.

Em suas diferentes manifestações, o Cordel é a única reconhecida e divulgada no mundo letrado e hoje é cenário de grandes pesquisas no âmbito nacional e internacional, que visam preservar e dar maior reconhecimento para a cultura popular, incluindo entre essas investigações alguns estudos, tem como discussão a importância do cordel no processo de ensino-aprendizagem.

Nessa perspectiva, o presente artigo tem como objetivo analisar a importância da inclusão da Literatura de Cordel, como uma ferramenta em sala de aula, no processo de ensino-aprendizagem e como este gênero pode auxiliar o professor a trabalhar novas habilidades e novos saberes junto aos alunos, de forma criativa e conexa.

O Cordel é um gênero que explora características da linguagem oral, que possibilita o desenvolvimento das habilidades comunicativas, pode ampliar o conhecimento de mundo dos alunos, já que neste tipo de gênero encontra-se uma variedade de temas relevantes para a sociedade. Pode despertar a capacidade crítica do aluno através das possíveis relações de significado histórico e social contextualizado nos discursos, a partir da leitura dos folhetos, que implica refletir e estimular os estudantes a pensarem sobre a complexidade das relações entre o ser humano e a sociedade. 
Portanto, ao trabalhar a Literatura de cordel, o professor estará promovendo aos alunos um riquíssimo universo da cultura popular, além de promover a valorização do patrimônio histórico cultural e da trajetória particular dos grupos que compõem a sociedade.

Os Parâmetros Curriculares Nacionais, (PCN's-1998), sugerem um ensino contextualizado, que potencialize o diálogo que percorre a cultura popular e a erudita, aprimorando os educandos, em uma sociedade multicultural.

Nesse sentido, esse estudo se justifica por conta da relevância de ampliar o conhecimento da Literatura de Cordel, por ser um gênero que está carregado de expressividade e historicidade relacionada à cultura popular e representativo da identidade do Nordeste. É um gênero que sustenta forte acervo de aspectos e visões de mundo que merece ser observado e aprofundado de maneira crítica em sala de aula.

A metodologia aplicada foi através de uma pesquisa básica, bibliográfica, com olhar para o PCN (1998), de natureza qualitativa, visto que esse tipo de pesquisa é muito usado para estudos de grupos sociais.

Falar sobre o Cordel é trazer os elementos mais significativos que as pessoas a ele conferem e traduzir para o ensino os aspectos mais relevantes deste gênero. Percorrer esses caminhos é chegar à ativa de aprofundar a discussão sobre a importância dos gêneros textuais. Embora, existem grandes bases teóricas para investigação dos gêneros, foi adotado um breve recorde dos estudos de Bakhtin e Marchushi.

Para que se compreenda melhor esse processo, Marchushi aponta que uma análise dos gêneros integra texto, discurso, uma descrição da língua e visão da sociedade. Assim, para investigação do gênero Cordel, a coleta de dados foi exploratória e descritiva, com abordagem teórica, nos estudos de Bakhtin (2003), Estética da Criação Verbal, onde o autor define a linguagem como uma ação constante mediada pelo diálogo, no qual ele descreve como "Gêneros Discursivos". Em contrapartida, 
Marchushi (2008), defende que gênero textual e tipo textual são elementos distintos que devem ser observados separadamente.

A visão de Candido (2006), em Literatura e sociedade tornou-se ênfase para o conhecimento construído através da arte literária, que possibilita uma ação transformadora pelos mecanismos que a própria literatura produz nos indivíduos.

Os trabalhos do professor Silvio Elias e Thelma Guimarães, sobre estudos linguísticos foi base para análise dos níveis da linguagem oral e escrita, que muitas vezes prende o indivíduo a um espaço restrito gerando a discriminação. Saber refletir sobre a língua e seu funcionamento é compreender os fenômenos do português falado e escrito no Brasil.

\section{HISTÓRIA DO CORDEL: VISÃO GERAL}

Embora, seu reconhecimento seja recente, no universo letrado, o Cordel já existia entre os povos antigos europeus como saxões, fenícios e greco-romanos. Iniciou em Portugal e na Espanha (Península lbérica) no século XVI, sendo chamado pelo primeiro país de "volantes" e pelo segundo de "pliegos sueltos" o nome "cordel" surgiu devido, em terras lusitanas, os folhetos serem expostos pendurados para comercialização em barbantes, cordões, que eram amarrados de um ponto a outro, como roupa em varal.

Herdeira do romanceio tradicional, a Literatura de Cordel, foi difundida através de histórias em versos que eram contadas por pessoas populares em peregrinação, o que contribuiu de uma forma considerável para o primórdio da literatura popular. As histórias estilo oral eram escritas em formato de folhetos, relatando viagens, aventuras e fantasias.

Trazidos pelos portugueses no século XVIII, o Cordel teve como berço a região Nordeste do país, devido Salvador ter sido a primeira capital brasileira com qualidades portuárias e de localização, o que a tornou referência para os navegadores. As histórias vindas de Portugal ganhavam adaptações, quando chegaram ao Nordeste, 
às temáticas mais diversas constituía-se de um grande repertório que contemplava contexto sociocultural, político e econômico da época, além de sonhos, fantasias e valores de um povo.

Barroso, (2006, p. 22):

(...) o hábito de decorar histórias, dos cantos de trabalho, as cantigas de embalar e toda sorte de narrativas orais trazidas pelos colonizadores vão sedimentando, na cultura brasileira, o costume de cantar e contar histórias, de guardar na memória os acontecimentos da vida cotidiana. Assim, pouco a pouco, foi se desenvolvendo junto ao homem brasileiro, mais especificamente na região nordeste, onde se deu o início da colonização, uma poesia oral com características muito peculiares.

Entre o imaginário da idade média, o misticismo e as crenças do ideário cavaleiresco e das histórias de Carlos Magno, surge como precursor da literatura de cordel no Brasil, Leandro Gomes de Barros, com a publicação dos seus livros em 1893, o primeiro a publicar, editar e vender seus poemas; modelo a ser seguido por vários poetas do gênero. Entre eles é importante citar o poeta Patativa do Assaré, um dos principais representantes da arte popular nordestina do século $X X$, os seus livros foram traduzidos em diversos idiomas e seus poemas tornaram-se temas de pesquisas na cadeira de Literatura Popular Universal da Universidade de Sorbonne, na França.

Vale lembrar o nome de João Martins de Athayde, poeta, editor e desbravador da indústria do folheto de cordel no país em 1921, ao comprar os direitos das obras de Leandro Gomes de Barros, de forma consolidada, iniciou a re-publicação fazendo crescer sua produção. Tornou-se editor de seus folhetos e também de outros cordelistas, foi responsável pela distribuição dos folhetos, passando a serem vendidos em grandes cidades de vários Estados.

Importante ressaltar que a maior disseminação do Cordel é na região Nordeste, mas existem poetas populares em outros polos como São Paulo, Norte do Paraná, parte 
de Minas Gerais e Goiás, etc.; que resulta em um vasto panorama que nos permite avaliar a grandeza da contribuição poética popular.

Os folhetos trazem em sua capa diferentes formas de ilustração, mas a xilogravura [2] merece destaque pela simplicidade de formas e com grande expressão visual carregadas de imaginários e sentimentos que aparecem nos folhetos na década de 1940 "e se deve, sobretudo, á pobreza dos poetas e editores em encontrar clichês de reticula ou outros recursos gráficos para ilustração de suas obras" (LUYTEM, 1983, p.257).

O Cordel, com o tempo transformou-se em uma arte genuína brasileira, mantendo sua essência e somando elementos da riqueza cultural da região nordeste. Em meio a tantas mudanças e renovação tecnológica, pode-se encontrar também o Cordel eletrônico, tornando-se mais visível, nacional e internacionalmente.

No entanto a cultura popular de modo geral ainda menosprezada pelas instituições do saber dominante, a uma grande conquista e reconhecimento da Literatura de Cordel como Patrimônio Cultural Imaterial Brasileiro, que recebeu o título em 19 de setembro de 2018, pelo valor cultural que contribuiu para difusão de expressões populares, valorização e proteção dos saberes.

Falar dos caminhos históricos literários e pôr o aluno com interação com os grandes pensadores, poetas e as mais diversas formas artes, das mais variadas culturas do mundo é um grande desafio para o ensino atual, é a resposta a esse desafio é dar ênfase como esses conhecimentos foram construídos. No ponto teórico isso implica "(re) descobrir" e "(re) construir novos conhecimentos". (BECKER, 2012, p.131).

\section{LITERATURA DE CORDEL X LITERATURA ERUDITA}

A cultura popular surge de costumes e tradições transmitidos de geração para geração, ela passou por diversas fases de incompreensão no passado e continua ainda em boa parte desconhecida e muitas vezes negada implícita ou explicitamente, 
por conta da origem humilde que gerou concepções e pontos de vista divergentes entre pesquisadores e estudiosos.

A separação entre a cultura popular e a cultura erudita foi uma invenção dos intelectuais europeus, na segunda metade do século XVIII, eles demarcaram fronteiras a partir do conceito folclore, termo criado pelo por Willian John Thoms, arqueólogo inglês, indicado para definir o saber tradicional, preservado pelas fontes orais entre os camponeses com o significado de antiguidades populares, literatura popular. Consequentemente desencadeou o início de muitas pesquisas folclóricas que se empenharam em descobrir uma cultura primitiva, que fosse pura e com resíduo do passado. Segundo estas pesquisas o contato com outras culturas estava condenado à morte devido à forte influência deletéria dos centros urbanos.

A partir do século $\mathrm{XX}$, após vários estudos sobre as manifestações populares que sobreviveram, um novo termo surge no lugar do restritivo folclore, e os estudos são elevados para uma nova categoria intitulada, Cultura popular. (BURKE, 1989; CERTEU; JULIA; REVEL, 1989, p.63 apud DOMINGUES)

Segundo Arantes (1990), O conceito cultura popular está muito longe de ser definido pelas ciências em função dos pontos de vistas extremos entre os pesquisadores, mas é importante ressaltar o que se qualifica popular e erudito é um tratamento de contrates de um e de domínio do outro.

É o que vem sendo percebido por vários estudiosos, que estes contrastes estão sempre em movimento, tornando indissociável a divisão entre eles, consideramos o fato de que existem tanto diferenças quanto semelhanças e há sempre um discurso que permite compreender o outro, revelando novos aspectos e novas profundidade de sentidos." Nesse encontro dialógico com duas culturas elas não se fundem nem se confundem; cada uma mantém a sua unidade e sua integridade aberta, mas elas se enriquecem mutuamente." (BAKTHIN, 2003, p.266).

Para elucidar, Ariano Suassuna[3], em "O Auto da Compadecida", sua peça mais conhecida, traz elementos em suas narrativas baseados na literatura de Cordel, que 
partiu dos episódios dos folhetos, Dinheiro (O testamento do cachorro), A História do Cavalo que defecava dinheiro, de Leandro Gomes de Barros; O Castigo da Soberba de Sílvio Pirauá de Lima. Segundo as palavras de Antônio Candido, Suassuna conseguiu relatar a realidade do sertão considerando os aspectos sociais e humanos mais relevantes da terra seca e de um povo lutador.

Por outro lado, percebe-se, que o Cordel também enriquece com as grandes obras consagradas da literatura universal, por ser um gênero literário que se apropria de vários temas e ao mesmo tempo inspiram várias outras manifestações artísticas. Vários poetas populares produzem a recriação textual de grandes romances consagrados; O sucesso de $\mathrm{O}$ Conde de Monte Cristo pode também ser comprovado pelo diálogo cultural entre o mundo letrado e o popular, onde as transformações aproximam da linguagem simples e ganham adaptações da grafia portuguesa.

Atualmente a Literatura popular, em especial o Cordel, chega aos grandes centros Universitários do Brasil, através de diversos artigos e teses, e é cenário de grandes pesquisas no âmbito internacional, que vem sendo estudados na França, em Portugal, na Alemanha e em outros países, que visam preservar e dar maior reconhecimento para a arte popular, incluindo entre essas investigações alguns estudos, que têm como discussão a importância do cordel como ferramenta auxiliar no processo de ensino-aprendizagem.

Os próprios poetas cordelistas também se voltaram para projetos de divulgação dos seus folhetos nas escolas. Cabe citar, acorda cordel na sala de aula, do cearense Arievaldo Viana Lima, que propõe a revitalização do gênero e sua utilização como ferramenta paradidática na alfabetização de crianças, jovens e adultos e também nas classes do ensino Fundamental e Médio. Entre tantos outros já adotaram essa ideia declamada em rimas, como ressalta, João Bosco Bezerra Bonfim no folheto: O cordel é a chama alegre da cultura brasileira:

\section{$[\ldots]$}

Há mais de cem anos luta 
o cordel deste País

para levar a mensagem

da cultura de raiz,

porém ouvidos se negam

a ouvir o que o cordel diz.

Não se pode deixar de citar os estudos de Ana Cristina Marinho e Hélder Pinheiro, que em suas obras valoriza o uso do Cordel, como um recurso didático no processo educativo. Os autores consideram que: "abrir as portas da escola para o conhecimento e a experiência com a literatura de cordel, e a literatura popular como um todo, é uma conquista da maior importância", visto que: "está provado que a linguagem poética tem o poder de propiciar experiências estéticas e sócias, de permitir reconhecimentos e diferenças entre indivíduos e culturas podendo inclusive mudar o rumo de vidas inteiras" (2012, p.7 grifos do autor).

Com base nessas afirmativas é possível constatar que o discurso poético amplia a compreensão do mundo, não como uma forma pronta capaz de mudar o plano físico, mas pela percepção que a linguagem traduz, resultando em uma resposta que conduz a um comportamento (OKAMOTO, 2002).

Nesse sentido, o conhecimento construído através da arte literária possibilita a capacidade transformadora pelos mecanismos que a própria literatura produz nos indivíduos, seja modificando a sua conduta, na concepção do mundo, ou reforçando neles o sentimento dos valores sociais (CANDIDO, 2006).

Para fazer florescer o leitor crítico, é preciso alçar a leitura à condição de instrumento de conscientização capaz de aguçar a criticidade do aprendiz, habilitando-o a compreender as contradições existentes na sociedade. (LIMA, 1995, p.107). 
Nesse ponto, chamo atenção especial para professor que ao abordar a Literatura de Cordel no ensino, ele tem um leque de possibilidades que podem ser exploradas entre a leitura e a realidade, tornando possível desenvolver o senso crítico do aluno, levando-o a perceber que essas produções muitas vezes de cunho social, trazem consigo não só as vozes dos problemas sociais do Nordeste, mas acusa problemas de todo país.

Refletir sobre a realidade na qual estamos inseridos é uma forma a perceber suas contradições e problemas, bem como caminhos para solucioná-los, tornando-se um grande desafio, contribuindo para a construção da verdadeira cidadania.

\section{A CONFIGURAÇÃO DO GÊNERO}

Já se tornou consenso que o trabalho com os gêneros no ensino é relevante, isso porque toda manifestação verbal se dá sempre por meio de textos realizados em algum gênero textual (MARCUSCHI, 2008). Por isso a centralidade da noção de gênero na relação sócio interativa da linguagem. Em decorrência a uma variedade de gêneros textuais quanto permite a esfera da atividade humana em que se produz a linguagem, como lembra (BAKHTIN, 2003).

O autor define a linguagem como prática discursivas, organizada dentro das atividades humanas. Nesse sentido, os gêneros do discurso como formas estáveis de enunciados elaborados de acordo com as condições específicas de cada campo da comunicação verbal. Essa definição remete interação discursiva que envolve o tempo, o espaço, os participantes, a finalidade, os meios de comunicação na sociedade. Assim, cada esfera produz seus próprios gêneros o que ele denominou "gêneros do discurso" (2003, p.262, grifos do autor).

Sob essa perspectiva, podemos compreender que os gêneros, são definidos como enunciados relativamente estáveis se apresentam flexíveis, dinâmicos e fluídos. Uma das diferenciações essenciais que ele se permite fazer é a classificação dos gêneros quanto às esferas de uso da linguagem. Os discursivos primários são espontâneos e se dá no âmbito da comunicação discursiva imediata, a linguagem do dia a dia. Já os 
secundários são produzidos com base em códigos culturais mais complexos e relativamente mais organizados predominante na escrita.

Compreende-se então, que a Literatura de Cordel é um gênero secundário e plurivocal, uma vez que se trata de uma manifestação artística, oral, dentro da cultura popular. Vale lembrar que, quando os gêneros primários se tornam componentes dos gêneros secundários, passam por uma transformação e adquire uma característica particular, o que isso significa é que gêneros são definidos como configurações recorrentes de significados, as quais, por sua vez, tornam possíveis as práticas sociais de uma dada cultura, seja através de gêneros orais ou escritos, literários ou não.

Por outro lado, (MARCUSHI, 2008, p. 155) defende que:

Os gêneros textuais são os textos que encontramos em nossa vida diária e que apresentam padrões sociocomunicativos característicos definidos por composições funcionais, objetivos enunciativos e estilos concretamente realizados na integração de forças históricas, sociais, institucionais e técnicas. Em contraposição aos tipos, os gêneros são entidades empíricas em situações comunicativas e se expressam em designações diversas, constituindo em princípio listagens abertas.

Para o autor tipo textual e gênero textual, duas noções, que, devem ser claramente distinguidas. Entende-se que os gêneros textuais são produtos históricos e sócios culturais construídos com objetivos específicos. Enquanto os gêneros parecem ser infinitos, os tipos textuais são cinco: narração, descrição, injunção, exposição e argumentação sem tendência a aumentar.

Como se nota, a questão de gênero envolve um conjunto de parâmetros para observação, tendo em vista a complexidade do fenômeno que envolve aspectos linguísticos, discursivos, históricos, culturais, interacionais, que são vinculados às atividades humanas em todas as esferas comunicativas.

É preciso considerar que o gênero textual teve seu lugar no ensino a partir dos PCN's (1998), logo muitos textos denominados populares conseguiram sua relevância na 
educação. Neste ponto a escola exerce a função de veículo capaz de proporcionar ao aluno, o contato com o maior número possível de gêneros textuais, fazendo com que eles sejam objetos de ensino e aprendizado, já que todo conhecimento sedimento é o referencial para assimilação de novos conhecimentos, tal como nos propõe (VYGOTSKY, 2007).

Assim, a diversidade dos gêneros textual ganha força em sala de aula, pois colocam o aluno em contato com uma gama de opções textuais, que consequentemente, fornecerão variadas visões de mundo que o levaram a compreender todas as possibilidades que esse horizonte oferece.

Vinculada a essa concepção, a Literatura de Cordel tem sua essência ligada à realidade $\mathrm{e}$, às práticas sociais que ampliam estes horizontes por favorecer a construção de saberes. Esse gênero é marcado por elementos que trazem consigo subsídios e informações culturais, já que neste tipo de gênero encontra-se uma variedade de temas relevantes para a sociedade, que abarcam desde folclore, política e religião, entre outros que habitam o imaginário popular, além da natureza poética dos seus folhetos.

É interessante reiterar que essas características informativas, circunstanciais, biográficas, documental entre outras, são conhecidas pelos pesquisadores por Ciclos Temáticos de Cordel, pelas diversidades dos temas encontrados nos folhetos. Essas pesquisas não têm somente o foco na proposta de sistematização da literatura de cordel, mas pelos caminhos que conecta com o social levando em consideração os acontecimentos da época. Classificação importante que podem ajudar o professor a escolher um tema, principalmente os atuais, pois o interesse aumenta a partir do momento que os alunos conseguem enxergar a importância e a aplicabilidade do que está sendo passado em sala de aula na sua vida.

\section{O PLANO SONORO}

A oralidade é entendida como uma atividade verbal presente nas mais diferentes situações sociais em que o indivíduo possa se inserir ao longo de sua vida. É a 
transmissão oral dos conhecimentos armazenados na memória humana. Por um lado, há um consenso que a fala é aprendida espontaneamente e não precisa ser ensinada, em contrapartida há teses que defendem que é preciso capacitar alunos para os diferentes modos de falar, próprios dos discursos das diversas esferas sociais.

$\mathrm{Na}$ verdade, a oralidade não tem ocupado um espaço muito amplo nas salas de aula, para desenvolvimento das habilidades comunicativas, que exigem a interação oral. Como visto anteriormente, os pensamentos Bakhtin (2003), favoreceu um olhar mais reflexivo dos textos orais, despertado o interesse de pesquisadores que buscam entender as novas propostas para o ensino da Língua Portuguesa apresentadas PCN's. É bom acrescentar ainda que:

Os gêneros do discurso organizam nossa fala da mesma maneira que a organizam as formas gramaticais (sintáticas). Aprendemos a moldar nossa fala às formas do gênero e, ao ouvir a fala do outro, sabemos de imediato, bem nas primeiras palavras, pressentir lhes o gênero, adivinhar-Ihe o volume (a extensão aproximada do todo discursivo), a dada estrutura composicional, prever-Ihe o fim [...]. Se não existissem os gêneros do discurso e se não os dominássemos, se tivéssemos de criálos pela primeira vez no processo da fala, se tivéssemos de construir cada um de nossos enunciados, a comunicação verbal seria quase impossível (BAKHTIN, 2003, p. 283)

Considerando a oralidade, como práticas discursivas e formadoras de inserção social, a Literatura de cordel surge é interessante proposta para desenvolvimento das habilidades orais em sala de aula, visto que oralidade é uma característica muito singular desse gênero repleto de expressividade, ritmo e musicalidade.

O cordelista, quando escreve o Cordel, ele destina ao público ouvinte e todas essas manifestações culturais ganham suporte dos folhetos impressos que é "um locus físico ou virtual com formato especifico que serve de base ou ambiente de fixação do gênero materializado como texto" e passam pelo campo da leitura (MARCUSHI, 2008, p. 174). 
Nesse momento é importante lembrar que o texto físico encontra-se no plano de conteúdo e a oralidade no plano de expressão.

No poema o ritmo é dado pela alternância das sílabas tônicas, átonas e das métricas formando a musicalidade, ferramentas que aliadas ao ensino podem ajudar o aluno a trabalhar com entonação da voz; baixa, alta e direcional. Não se pode deixar de lembrar que a ênfase e a duração das vogais no ato da fala é também um recurso importante na comunicação assertiva, atualmente um dos principais requisitos para atuar no mercado de trabalho e da mesma forma podem ser exploradas através do Cordel.

Bakhtin chama atenção para a importância da entonação, que por meio desse recurso são assimilados os enunciados, por estar entre o contato do falante com o ouvinte. Pode-se inferir que "a entonação é social par excellence[4]" por estar diretamente ligada com as práticas discursivas (2003, p.449 grifos do autor).

Falar bem não significa ter um vocabulário erudito, mas envolve todo processo de comunicação e clareza, para não gerar incompreensão. Nesse sentido, a linguagem simples do Cordel ajuda na correta dicção das palavras. Dessa forma leva o aluno autoconfiança e a diminuir a ansiedade ao falar em público.

\section{SABERES LINGUÍSTICOS}

Ao refletir sobre o falar bem, leva a uma reflexão sobre as variedades linguísticas e como essas variedades muitas vezes são discriminadas pelos traços que marcam a fala.

As línguas são resultados de uma evolução histórica no tempo e no espaço. Tal transformação ocorreu com o impacto da renovação cultural dos séculos XV e XVI, sob a influência do Renascimento italiano, do contato com as culturas gregas e latinas e com a expansão ultramarina que permitiu aproximação da língua portuguesa com várias línguas do mundo. 
Desse modo, durante todo o século XVI foi um momento decisivo para expansão da Língua Portuguesa no seu espaço de origem e dos impérios conquistados, intensificando-se os contatos da linguagem, com falantes de áreas geográficas dos mais diversos povos e outras culturas, deixando de pertencer apenas a Portugal e tornando-se uma conexão de comunicação entre nações distantes e diversas.

Com o crescimento e instalação do comércio em várias regiões do Oriente e abertura de portos possibilitou a formação das "Línguas Crioulas", sobrepondo às línguas nativas, autóctones, e a de constituição de crioulos de base portuguesa. Deste modo o português se enriquece e se diferenciam de sua matriz continental, favorecendo o desenvolvimento da variedade de sua unidade, em outras palavras as múltiplas possibilidades de uso da Língua. Para o professor Sílvio Elias em sua obra "A língua portuguesa no mundo, " esses espaços geolinguísticos, Ele denomina de "Lusitânia" (1989, p. 17).

Em seus ensaios, Guimarães (2012, p.29.30), afirma que isso acontece porque o Português e todas as línguas são viva, dinâmica e estão sempre no processo de inovação e mudança. Esse movimento chamado de variação linguística afasta de sua unidade mais estável absorvendo novas palavras. No que se refere a esse movimento que ela chama de força centrifuga, não apenas age sobre a língua, pois dessa maneira em alguns séculos o português iria transformar em outro idioma ou cada falar regional iria se tornar um dialeto ou novas línguas. Em vista disso no Brasil não teria mais o português, e sim o baianês, o gauchês, o paulistês... .

O fenômeno relacionado ao uso da Língua Portuguesa é representado pela variação linguística, que ocorre no contexto histórico, geográfico e sociocultural e decorrem nas diferentes sociedades, visto que as línguas são heterogêneas. Elas variam tanto sob o ponto de vista diacrônico, quanto do ponto de vista sincrônico e recebem outras designações os quais dependem de fatores específicos.

Toda essa variação gera, muitas vezes, o preconceito linguístico, resultando à discriminação. Os textos do Cordel cumprem a função também de ferramenta intermediária, por conter tópicos de análise linguística que leva o aluno a refletir como 
a linguagem de fato seja chamada de linguagem padrão, linguagem culta, que muitas vezes prendem os indivíduos ao um espaço restrito gerando a exclusão das classes com maior poder social.

Com o advento da Linguística seus estudos apontam para os vários níveis de linguagem tanto da oralidade como da escrita. Apesar de haver correlação entre fala e escrita, em um espaço literário é possível a transcrição oral para a escrita, mantendo seu código para que os objetivos do discurso sejam alcançados. Exemplo disso são os cordéis de autoria de Patativa do Assaré que traz traços da oralidade, entre alguns deles para exemplificar: "Coisas do Meu Sertão", que tem a voz direcionada para os elementos mais singulares do Sertão incluído a variação linguística:

"Seu dotô, que é da cidade

Tem diproma e posição

E estudou derne minino

Sem perdê uma lição,

Conhece o nome dos rios,

Que corre inriba do chão,"

\section{$[\ldots]$}

Cumpre evidenciar também, que vários aspectos, da língua falada vão se distanciando cada vez mais da gramática normativa e que algumas regras impostas pela norma padrão, não são mais utilizadas o tempo todo, mesmo com as pessoas mais escolarizadas. Isso ocorre pelo fato de as variações linguísticas estarem, presente na fala descontraída e sem formalidade.

Segundo Guimarães, existem várias situações na vida acadêmica e profissional em que precisamos nos expressar oralmente de maneira formal (2012, p.47). 
Esses saberes linguísticos é uma das formas de aproximar os alunos das mudanças que ocorrem na língua portuguesa, por meio de textos que consigam traduzir o valor da linguagem, além de proporcionar uso correto dessas variantes devido à flexibilidade constante, de acordo com o espaço social.

\section{CONSIDERAÇÕES FINAIS}

Com advento da globalização, estamos vivendo em um mundo acelerado, onde a tecnologia tem ganhando cada vez mais espaços, elevando consideravelmente o acesso à informação e ao conhecimento.

Nesse cenário, muitos saberes tradicionais está se perdendo no caminho, entre eles os valores culturais presente nas mais diversas regiões que fazem parte da identidade do nosso país. Diante desse aspecto, a escola, como formadora de conhecimento, precisa abrir espaço cada vez mais, para as mais diversas culturas, como forma de disseminar e promover a valorização do patrimônio histórico cultural brasileiro e da trajetória particular dos grupos que compõe esse universo.

Tendo em vista os aspectos observados, conclui-se a importância da cultura popular em especial a Literatura de Cordel, para difusão desses saberes e valorização da diversidade cultural de um país que é tipicamente multicultural em sua formação.

O Cordel como ferramenta em sala de aula, como foi apontado ele percorre várias áreas dentro do ensino da Língua Portuguesa, promovendo aos alunos uma reflexão crítica, que pode ser alçada com a leitura dos folhetos, ampliando conhecimento de mundo, gerando conscientização sobre as contradições que existem na sociedade e as possíveis relações entre o popular e o erudito.

Levando-se também em consideração as competências comunicativas, está pesquisa apontou que as habilidades comunicativas podem ser exploradas com a Literatura de Cordel, de forma a construir um aluno seguro no seu discurso e com capacidades de utilização das variantes encontradas nas diversas formas de uso da Língua Portuguesa, de acordo com a esfera social. 
Diante dessas considerações, a Literatura de Cordel é uma ferramenta que pode ajudar o professor em sala de aula na construção de saberes dos alunos e desenvolvimento de novas habilidades.

\section{REFERÊNCIAS}

ARANTES, Antônio Augusto. O que é Cultura Popular. 1. ed. São Paulo: Hedra,1982. ASSARÉ, Patativa do. Uma Voz do Nordeste. 2.ed. São Paulo: Hedra, 2005.

BAKHTIN, Mikhail. Estética da Criação Verbal. 4. ed. São Paulo: Martins Fontes, 2000.

BARROSO, Maria Helenice. Os cordelistas no D.F.: dedilhando a viola, contando a história. 2006. 168 f. Dissertação (Mestrado em História) -Universidade de Brasília, Brasília, 2006.

BECKER, Fernando. Educação e Construção do Conhecimento. 2. ed. Porto Alegre: Penso,2012.

BONFIM, João Bosco Bezerra. O cordel é a chama alegre da cultura brasileira. Disponível em: <www. http://joaoboscobezerrabonfim.com.br/o-cordel-e-a-chamaalegre-da-cultura-brasileira/>. Acesso em 09 mai. 2019.

BRASIL. Ministério da Educação. Parâmetros Curriculares Nacionais para o Ensino Médio. DFMEC/SEF. Brasília, DF, 1998.

CANDIDO, Antônio. Literatura e Sociedade. 9. ed. Rio de Janeiro: Ouro Sobre Azul, 2006.

DOMINGUES, Petrônio. Cultura popular: as construções de um conceito na produção historiográfica. História, Franca, v. 30, n. 2, p. 401-419, Dez. 2011. Disponível em: <http://www.scielo.br/scielo.php?script=sci_arttext\&pid=S010190742011000200019\&lng=en\&nrm=iso >. Acesso em 09 Mai 2019. 
ELIA, Sílvio. A Língua Portuguesa no Mundo. 1. ed. São Paulo: Ática, 1989.

GUIMARÃES, Thelma de Carvalho. Comunicação e Linguagem. 1. ed. São Paulo: Pearson, 2012.

LUYTEN, Joseph M. O que é Literatura Popular. 2. ed. São Paulo: Brasiliense,1983. MAIA, Ana Cristina; PINHEIRO, Helder. O Cordel no Cotidiano Escolar. 1.ed. São Paulo: Cortez, 2012.

MARCUSCHI. Luiz Antônio. Produção Textual Análise de Gêneros e Compreensão. 1.ed. São Paulo: Parábola Editorial ,2008.

OKAMOTO, J. Percepção ambiental e comportamento. 1.ed São Paulo: Editora Mackenzie,2002.

VYGOTSKY, Lev S. A formação social da mente. 4.ed São Paulo: Martins Fontes, 2007.

\section{APÊNDICE - REFERÊNCIAS DE NOTA DE RODAPÉ}

2. Gravura em madeira, técnica antiga, de origem chinesa, em que o artesão utiliza um pedaço de madeira para entalhar um desenho utiliza para pintar a parte em relevo. Um detalhe importante é que o desenho sai ao contrário do que foi talhado, o que exige um maior trabalho do artesão.

3. Ariano Suassuna (1927- 2014) foi um escritor brasileiro, nasceu no Palácio da Redenção, na cidade de Nossa Senhora das Neves, hoje João Pessoa, capital da Paraíba, Fundador do Movimento Armorial que teve início nos anos 70, ele defendia a junção entre o erudito e os elementos da cultura popular nordestina.

4. Termo em francês usado na obra de Volochínov, V.N. "A palavra na vida e a palavra na poesia"

Enviado: Janeiro, 2020. 
Aprovado: Julho, 2020. 